\title{
Impact of Language Barriers on Patient Education: A Scoping Review
}

\author{
Mehraban Shahmari ${ }^{1}$, Marzieh Hasanpour ${ }^{1 *}$ \\ 1. School of Nursing and Midwifery, Tehran University of Medical Sciences, Tehran, Iran
}

Received: 22 April 2021

Accepted for publication: 20 March 2020

[EPub a head of print-7 June 2021]

Payesh: 2021; 20 (3): 301-310

\begin{abstract}
Objective (s): The purpose of patient education is creating positive behaviors. However, one of the biggest barriers of effective patient education and communication is differences of language between patients and health care providers. This study aimed to review the impact of language barriers on patient education worldwide.

Methods: In this scoping review, papers both in Persian and English related to patient education language barriers were searched using the following databases: PubMed, Embase, Scopus, and Web of Science, ProQuest, Science Direct, Springer, Cochrane library, Google Scholar, MagIran, SID, Iran Doc, IranMedex and Elmnet during 2010 to 2020 . The keywords included communication barriers, language barriers, communication, patient education, Bi language, language obstacle in both Persian and English.

Results: In all 8900 citations were retrieved. Of these 16 studies were relevant included in this study. The results of the studies showed a clear association between limited language skills and difficulty in communicating with patients and providing effective patient education, regardless of the research settings.

Conclusion: There is a close relationship between language skills and the provision of educational services to the patient. Lack of sufficient language skills prevents effective communication with patients. However, the limitations of studies that have only examined the effect of language barriers on effective patient education are evident, and there is a need for further studies on the topic.
\end{abstract}

Key Words: Patient education, Language Barriers, Scoping Review

\footnotetext{
* Corresponding author: Tehran University of Medical Sciences, Tehran, Iran

E-mail: m-hasanpour@sina.tums.ac.ir
} 


\title{
تأثير موانع زبان بر آموزش به بيمار: يك مرور دامنهاى
}

\author{
مهربان شهمارى'، مرضيه حسن بور \\ ا. دانشكده برستارى و مامايى، دانشكاه علوم يزشكى تهران، تهران، ايران

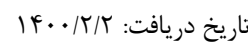

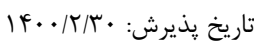

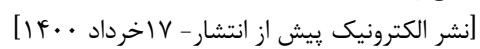

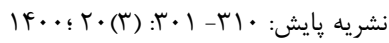

جـكيده

مقدمه: هدف از آموزش به بيمار ايجاد رفتارهاى مثبت در بيمار است. با اين وجود يكى از بزركترين موانع إنعان در اجراى آموزش و ارتباط مؤثر با بيمار، تفاوت

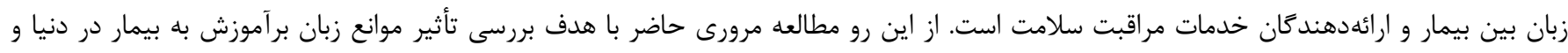
ايران انجام شده است. مواد و روش كار: در اين مطالعه مرورى دامنهاى، مطالعات با هر نوع طراحى در زمينه تأثير موانع زبان برآموزش به بيمار، بـ به دو دو زبان بان فارسى و انكليسى، در

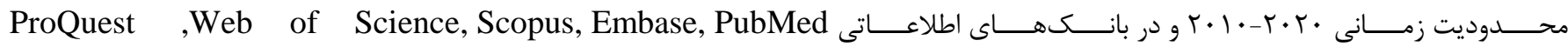
Iran Doc, SID, MagIran, DirectSpringer,Cochranelibrary,Google Scholar, Communication Barriers, language barriers, communication, Patient education different language, Bi Language obstacle, Language و و معادل فارسى آنها جستجو شد.

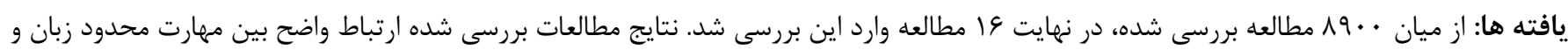

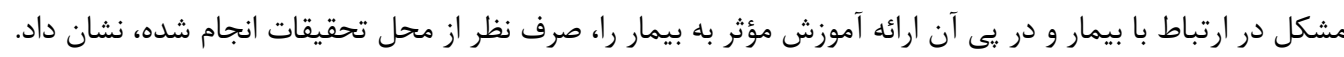

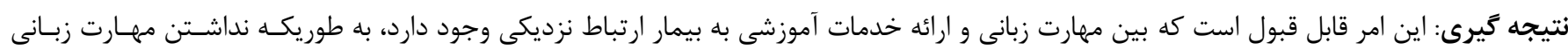

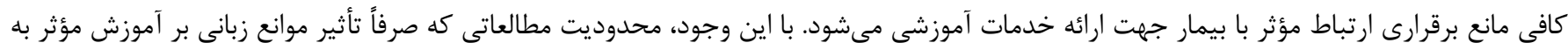

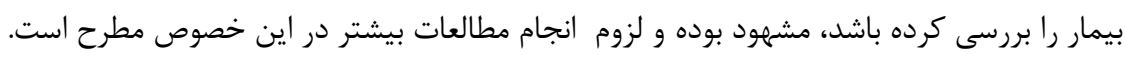




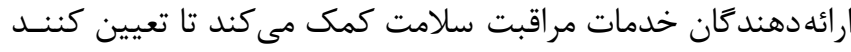

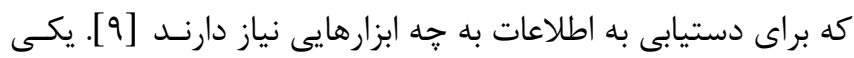

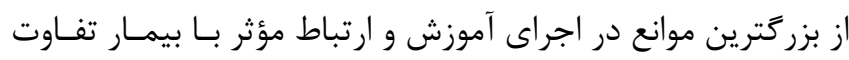

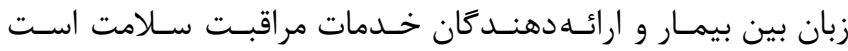

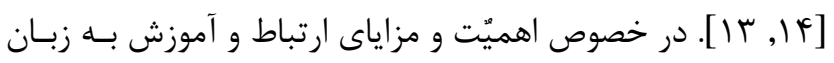

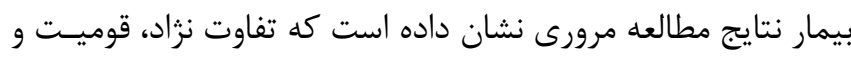
زبان بر كل كيفيت رابطه ارائهدهندًان خدمات سـلامتى و بيمـاران

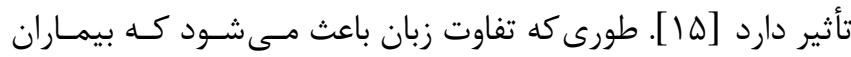
كمتر با ارائهدهندكان خدمات سلامتى رابطه بر قرار كنند، اطلاعـات

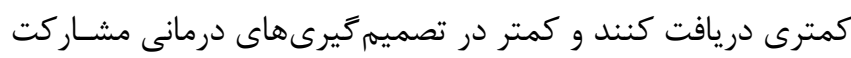

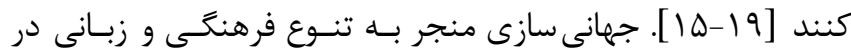

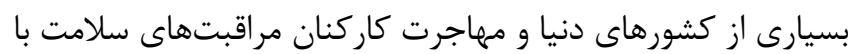

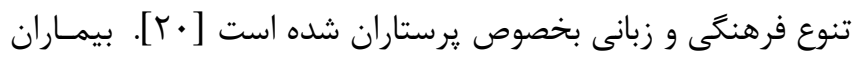

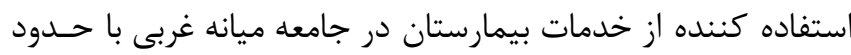

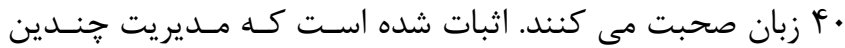

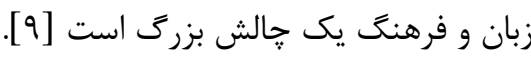

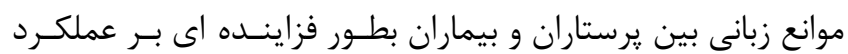

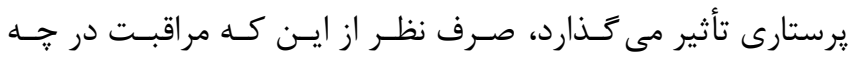

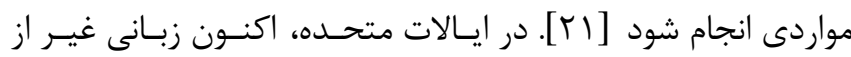

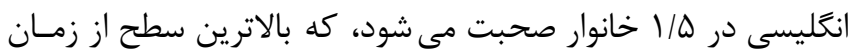

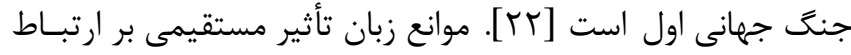

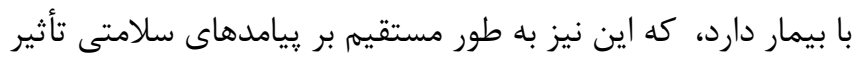

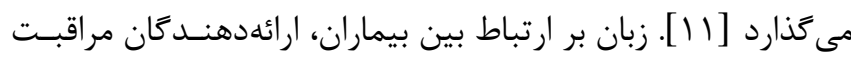

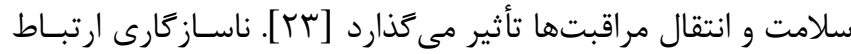

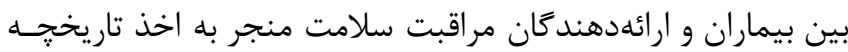

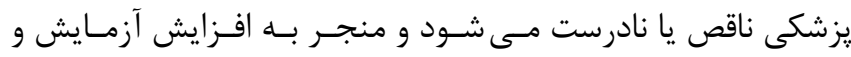

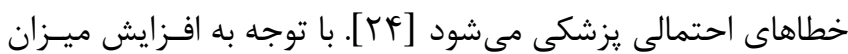

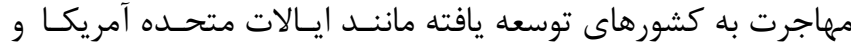

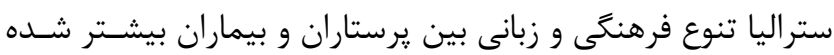

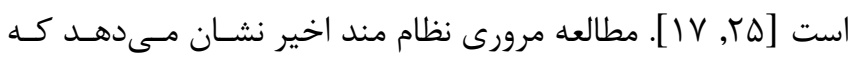
جنين موانع ارتباطى براى بسيارى از كشورها معمول است و آنها بر

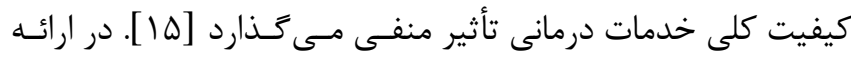

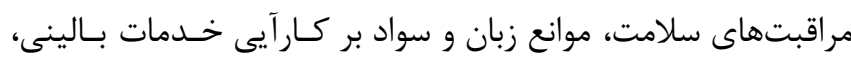
تصميم كيرى يزشكى، يايبندى به دارو و درك بيماران و دسترسى

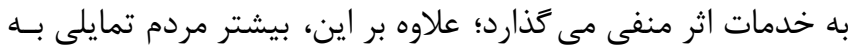

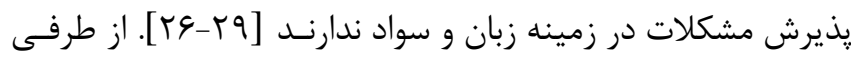

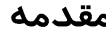

ارتباط مؤثر و كيفيـت آن از اهميّت اساسـى در تعامـل آموزشى و و

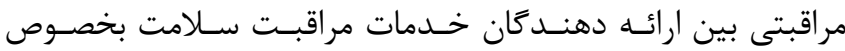

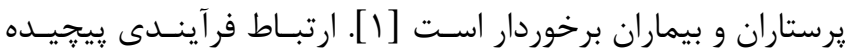

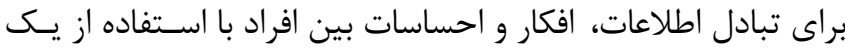

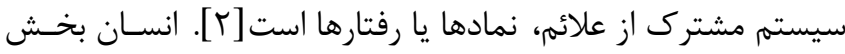

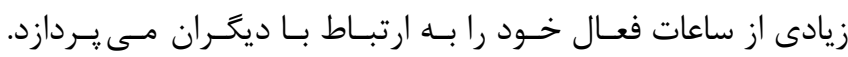

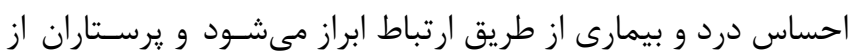

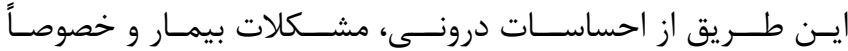

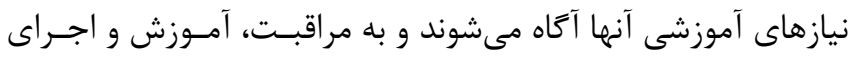

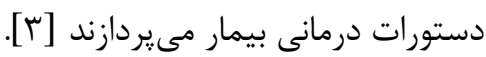
آموزش مؤثر بيمار فراتر از ارائه اطلاعات است و اثرات درات مفيد بسياري دارد كه در يزوهش هاى مختلف مورد بررسى قرار كرفته است. نتايج

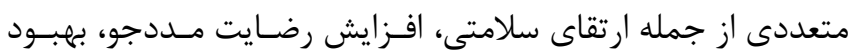

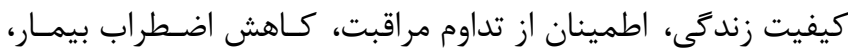

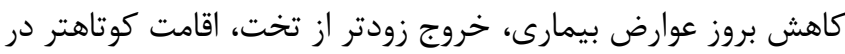

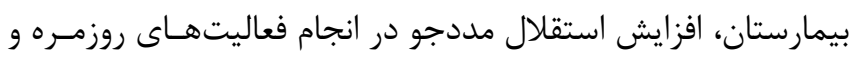

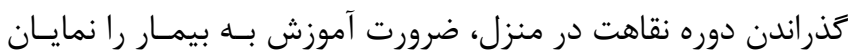

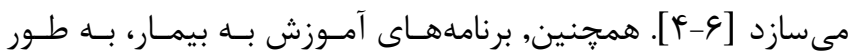

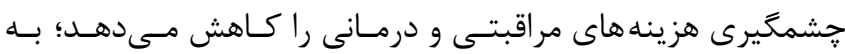

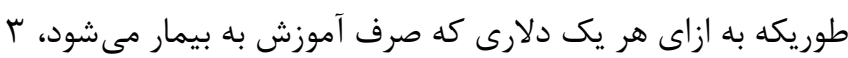

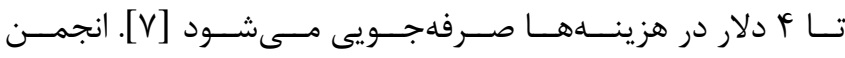
بيمارستان هاى آمريكا نيز آموزش را حق قـانونى مـددجويان اعـلام

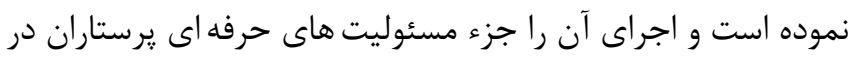

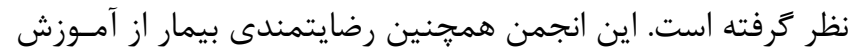
را يكى از شاخص هاى سنجش كيفيـت عملكـرد يرسـتاران معرفى إنى

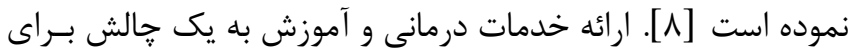
ارائه دهندكان تبديل شده است. يرستاران و إنائ ساير متخصصان روزانه

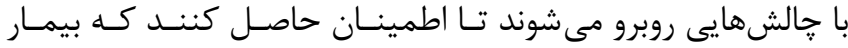

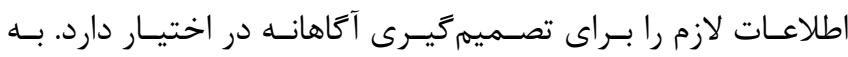

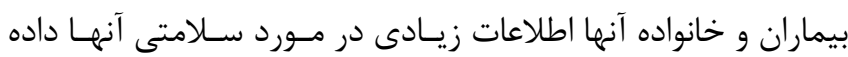

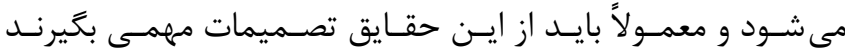

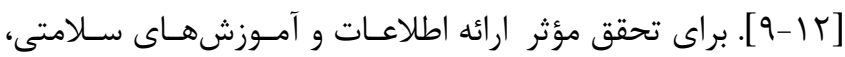

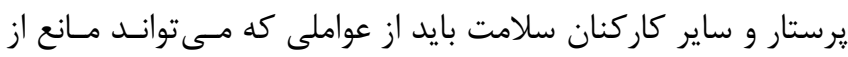

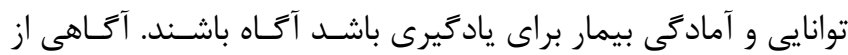

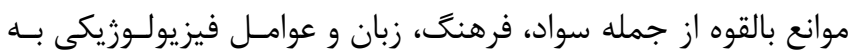




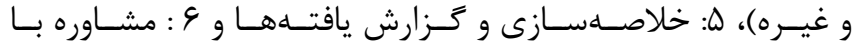

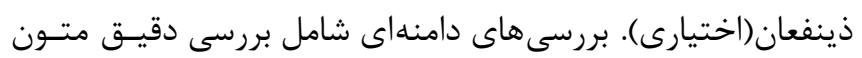

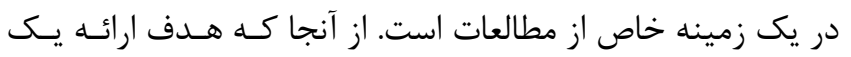

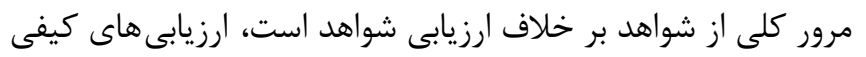

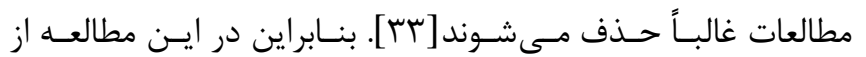

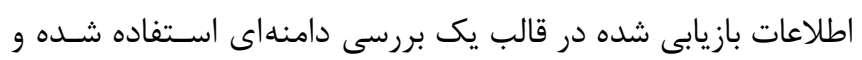
هيج ارزيابى انتقادى از مطالعات انجام نشده است. بررسى دامنهاى حاضر توسط سؤالات تحقيق زير هدايت شد:

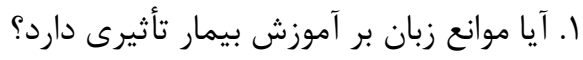

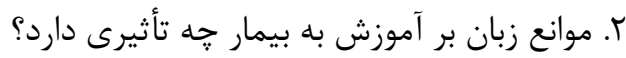

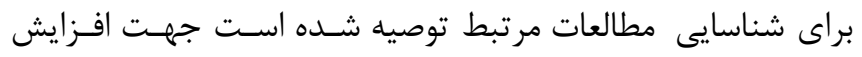

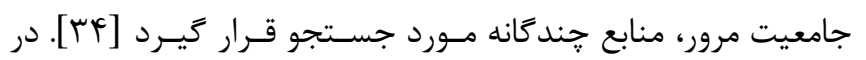

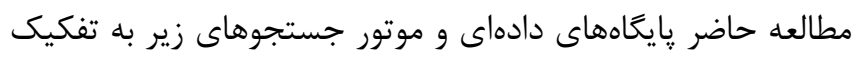
زبان קاب متون، مورد جستجو قرار ترفتند:

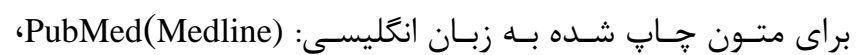
Science ‘ProQuest rISI Web of Science ،Scopus rEmbase Cochranelibrary ،springer ،Direct

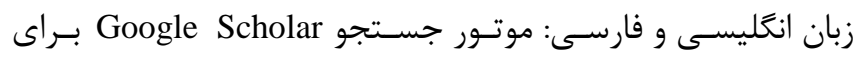

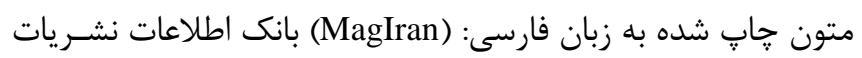

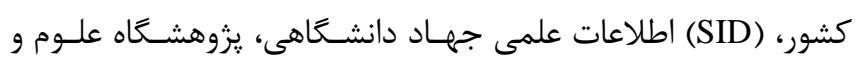
فنـاورى اطلاعـات ايـران(Iran Doc)، (IranMedex) سـامانه دانـش گستر بركت و موتور جستجوى Elmnet.

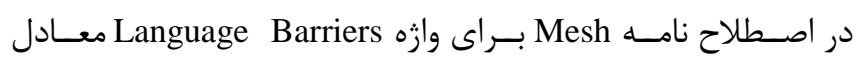

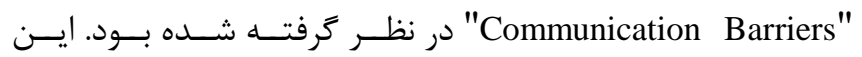

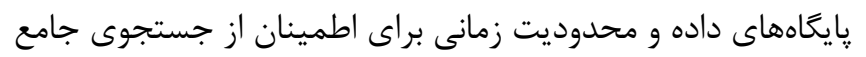

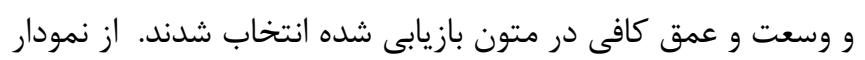
PRISMA-ScR (Scoping

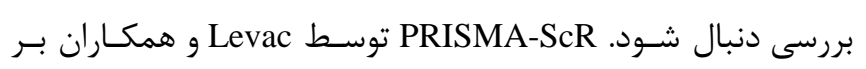

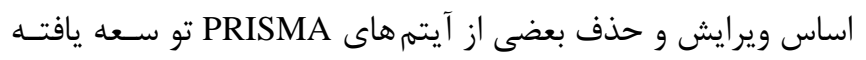

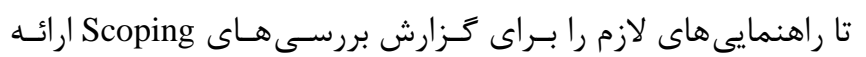

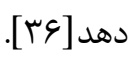
معيارهاى ورود و خروج مطالعات در حين انجام جستجوها و مطالعه

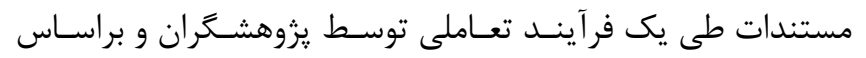

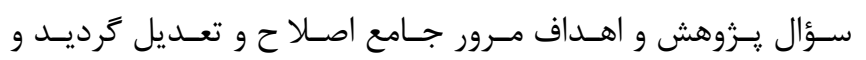

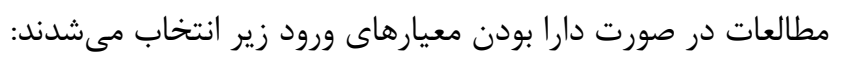

مداخلات آموزشى ساده، كوتاه و متناسب با فرهنگ و زبان بيمـاران

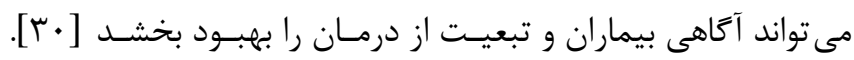

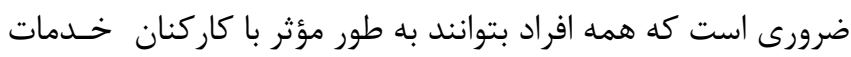

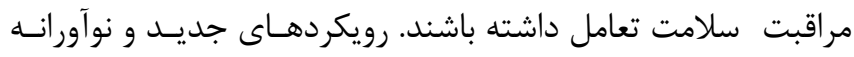

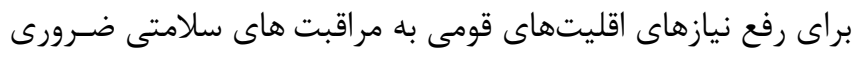

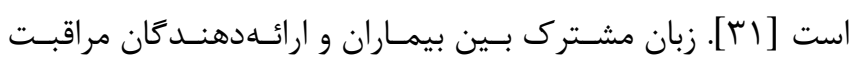

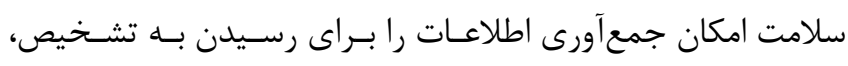

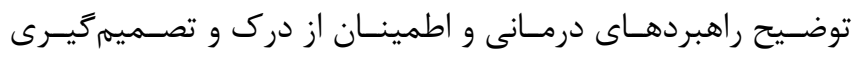

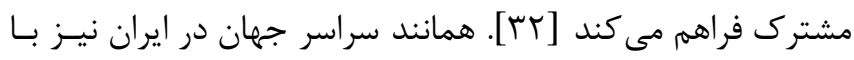

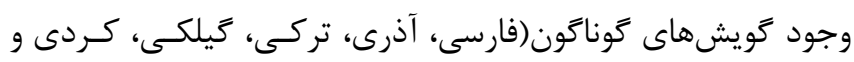

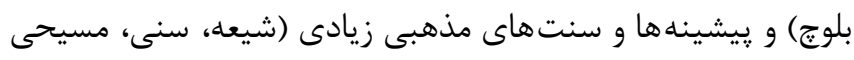

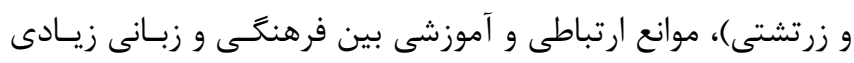

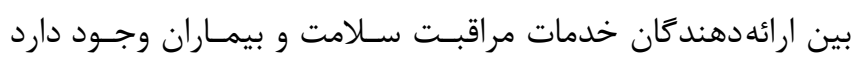

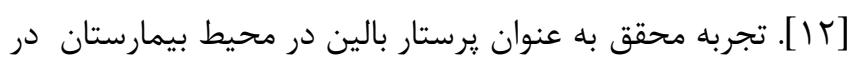

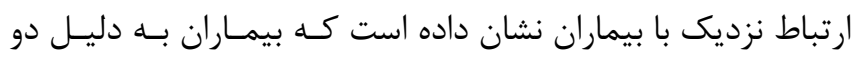

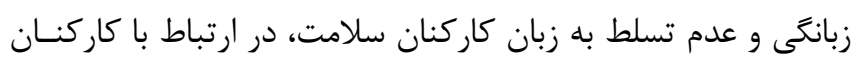

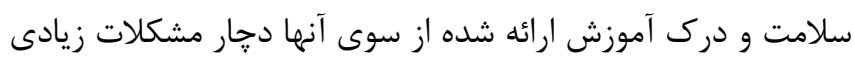

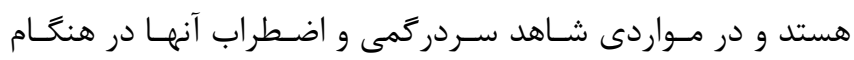

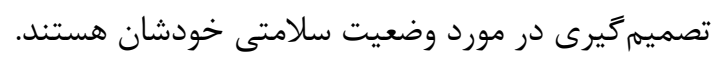

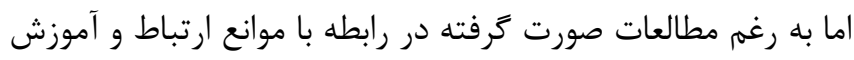

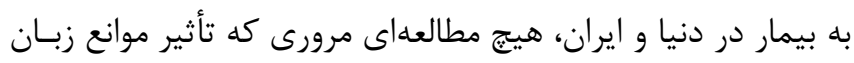

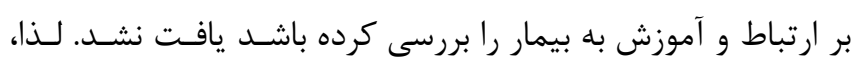

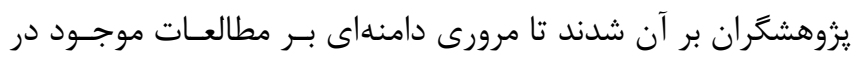

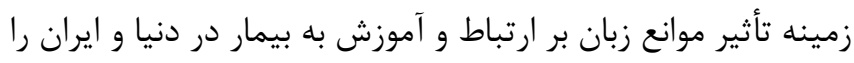

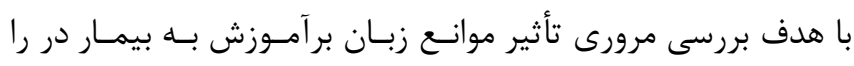

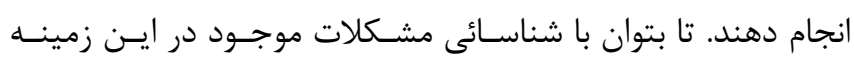
راهكارهاى صحيحى ارائه داد.

\section{مواد و روش كار}

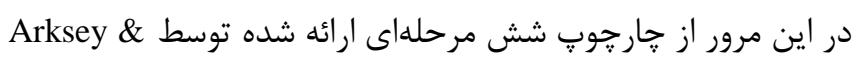
(T) O'Malley

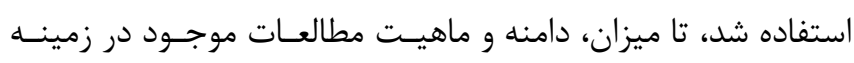

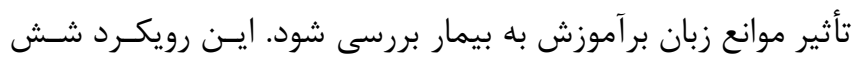

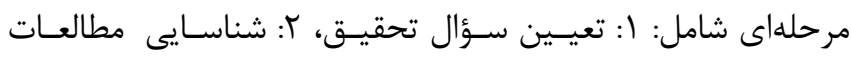

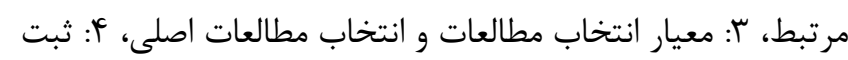

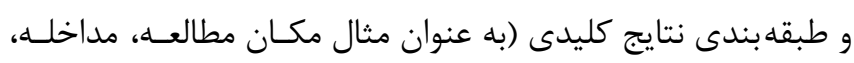

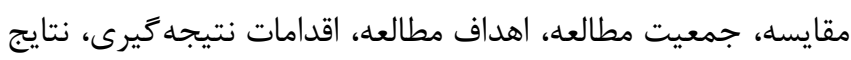


ورود، f مورد به دليل مرتبط نبـودن محـيط مطالعـه بـا معيارهــاى

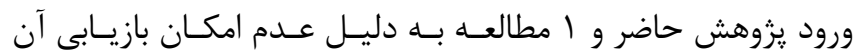

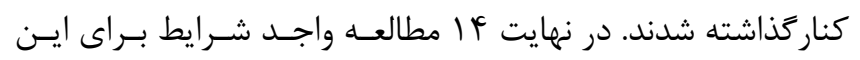

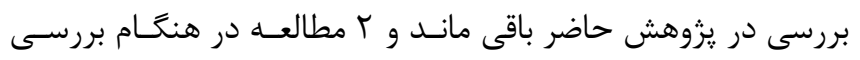

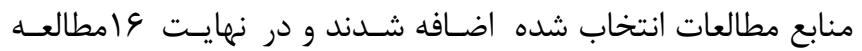

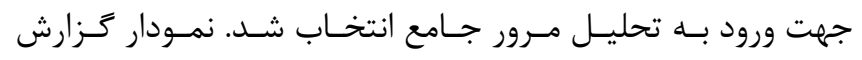
ترجيحى براى بررسى هـاى نظـام منــد دامنـهـ اى (PRISMA-ScR) جارت شماره ا بيانخر فرآيند است برتئ.

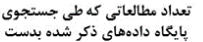

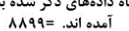

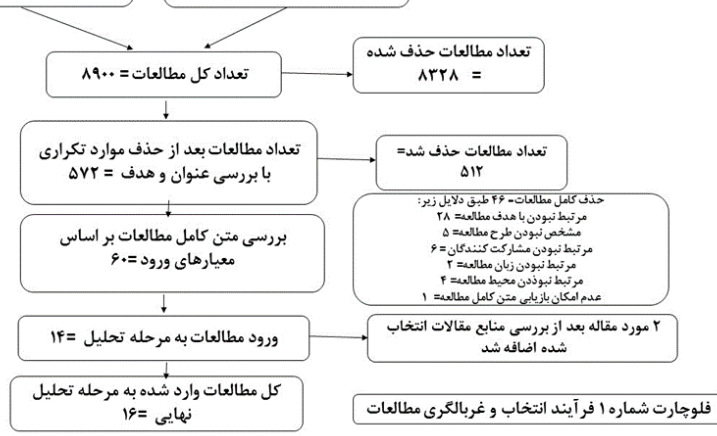

براى ثبت و طبقه بندى نتايج كليدى فرم استخر اج دادههـا طراحسى

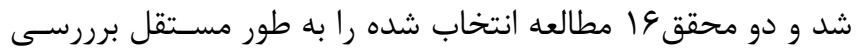

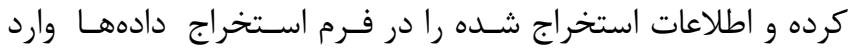
كردند كه شامل اطلاعات زير است.

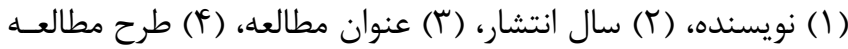
و (ه) يافته هاى كليدى كه مرتبط با سئوال بررسى است. مشخصات مطالعات مرور شده، در جدول ( شماره () آمده است.

يافتهها

از ميـان عامطالعـه مـورد بررسـى ها مــورد مقالـه(كمى، كيفى و مرورى) و يك مورد يايـان نامــه بـود، 9 مـورد مطالعـهـ كمى(نيمـهـ تجربسى: ا مــورد، توصــيفى مقطعسى: أمــورد، توصـيفى: أمسورد،

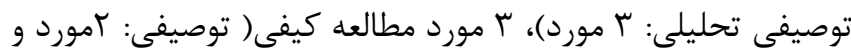
تحليل محتوا: ا مورد ) و \& مورد مطالعه مرورى (مرور نظام مند: 1 مورد، مرورى ساده: † مورد و روايتى: ا مورد) بود. 1 مــورد مطالعـهـ

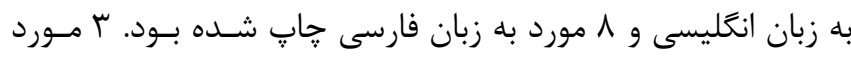

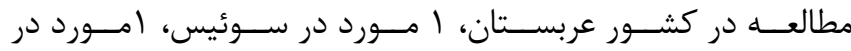

انغليستان، r مورد در آمريكا و 9 مورد در ايران انجام شده بود.

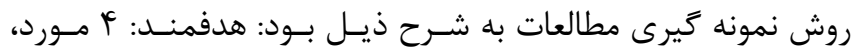

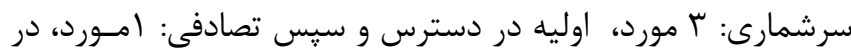
دسترس: ا مورد، تصادفى طبقات: 1 مورد، تصادفى ساده: 1 مـورد، أمورد،
- جمعيت: مشاركت كنندگان در مطالعات در محدوده سنى بـالاتر از 1ا بودنــد و در صــورت داشــتن اخــتلال ســــح هوشـــارى و

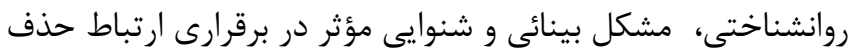
مى شدند. - مكان: بيماران بسترى در مراكز درمانى دولتى و خصوصى

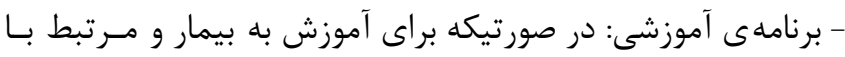
موانع زبان طراحى شده باشد. - طرح مطالعه: تمامى مطالعات بـا طـرح كمسى، كيفىى، تركيبـى و

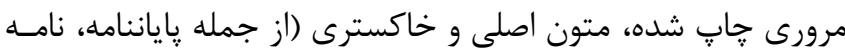

به سردبير و... )

- زبان انتشار: مطالعات منتشر شده به زبان فارسى و انخليسى

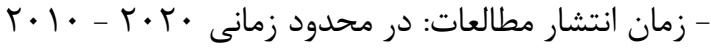

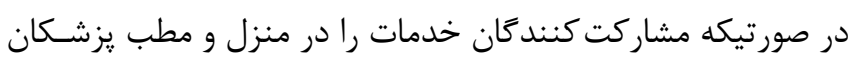
دريافت مى كردند از مطالعه حذف مى مدند. جهت بررسى و انتخـاب مطالعات مرتبط يس از يافتن آنهـا، توسـط دو محقـق مطالعـات بـا

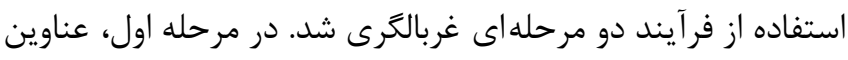

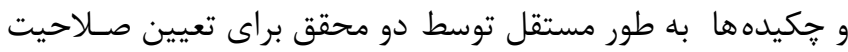

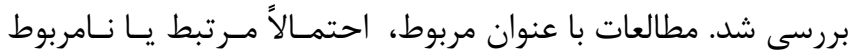

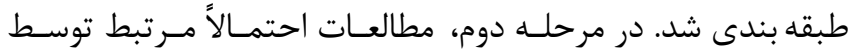

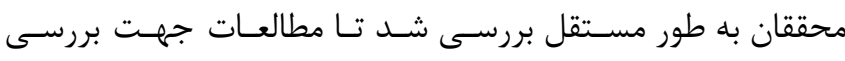
صلاحيت نهايى تعيين شود. محققان براى حل اختلافات و دستيابى به اجماع در هر دو مرحله گرد هم آمدند. ليستـهـاى منـابع تمـام

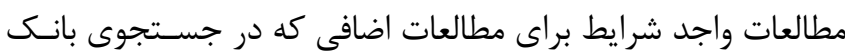

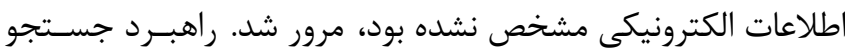
در هر يايگًاه داده مستندسازى و ذخيـره مسى شـد. همجنــين نتـايج جستجو در ابزار مديريت منابع EndNote-X8 ذخيره شد.

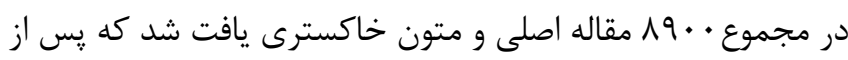

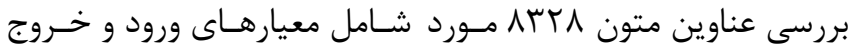
نبوده و توسط محققان حذف شدند. DVY مورد باقى مانده بر اساس موري

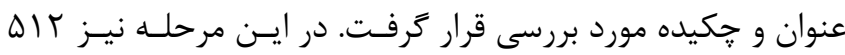
مورد بر اساس معيارهاى خروج حذف و •9 مقاله متن كامـل بـراى بازيابى و ارزيابى براى صلاحيت بررسى شدند. از اين تعداد \&\& مورد

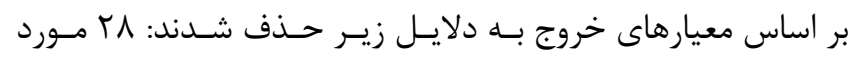

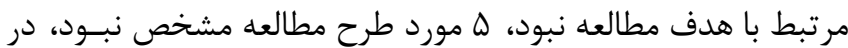

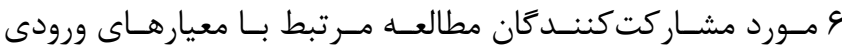
يزوهش حاضر نبودند، r مورد مرتبط نبودن زبان مطاله با معيارهاى 
نشريه يروهشكده علوم بهداشتى جهادانشگاهى

بيمار نسبت به ساير عوامل كم گزارش شده بود. از 19 مطالعـه بررسىى شده در \ مورد مطالعه موانع زبـان در بررسـى موانـع ارتبـاط بـا بيمـار

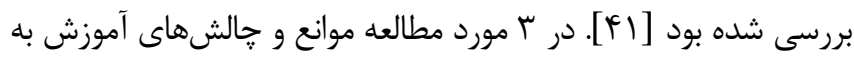

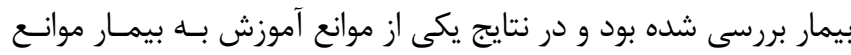

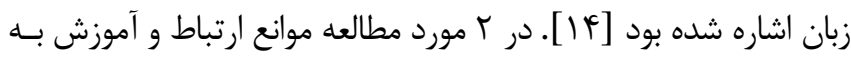
بيمار در كنار هم بررسى شده بود و در نتايج يكى از موانع مـؤثر در ايسن إنـ

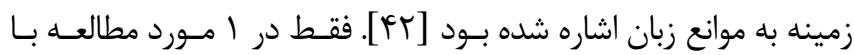

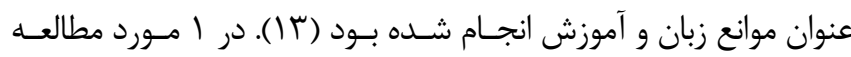

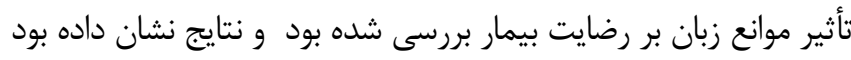

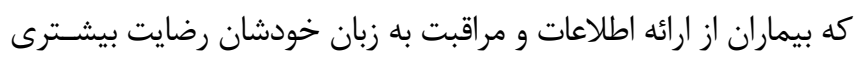

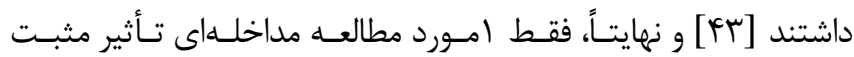
آموزش به زبان اصلى بيمار را بررسى كرده بود [FF].
ا مورد اشاره نشده بود و ₹ مـورد مقـالات مـرورى بودنـد. روش جمـع

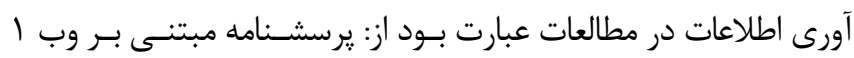

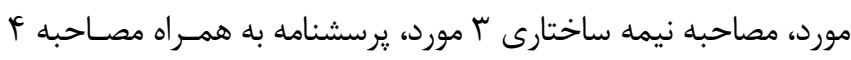

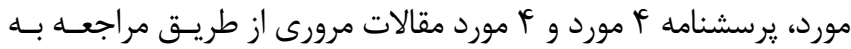
يايگاه داده ها و مرور متون بود. نمونه ها از كاركنان گَروه سـلامت(كروه

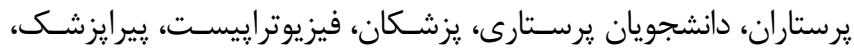

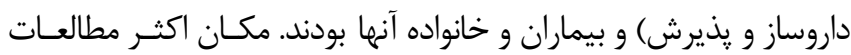

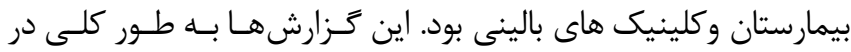
نشان دادن ارتباط واضح بين مهارت كافى زبان و ارتباط و آموزش مـؤثر

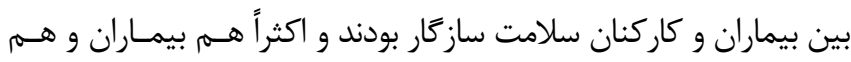

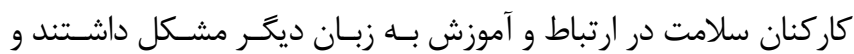

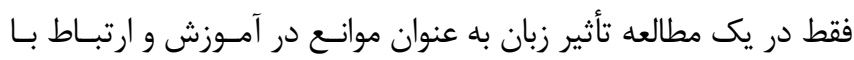

جدول ا: مشخصات مطالعات مرور شده مر تبط با تأثير موانع زبان بر آموزش به بيمار

\begin{tabular}{|c|c|c|c|c|}
\hline نتايج & & نوع مطالعه & 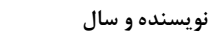 & 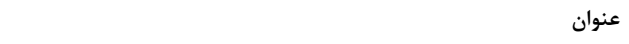 \\
\hline 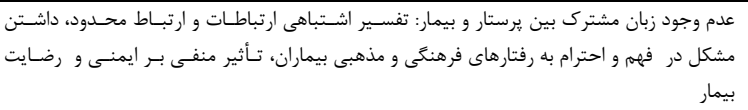 & & مرور يكيارحه & Alshammari(2019) & موانع ارتباط يرستار با بيمار در عربستان سعودى: مرور يكيارجه \\
\hline مضآموش مؤثر يرستارى بر بيماران اصمّيت زبان بر آموزش فردى، نيازهاى آموزشى و مراقبت. تأثير منفى موانع زبـانى بـر & & 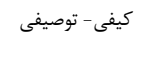 & Shubayra(2015) & دياليز صفاقى سريائى مداوم: تجربيات يرستاران از آموزش بيماران \\
\hline 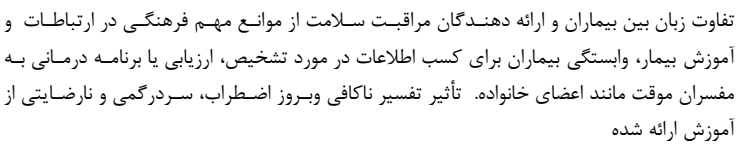 & تحيل & محتى إ رويكرد & Farahani(2011) & موانع ارتباطى براى آموزش بيمار در مراقبت هاى بسترى قلب: يــ مطالعـه كيفى \\
\hline وجود مشكل در ارتباط و آموزش با بيمار با فرهنَ و زبان متفاوت & & 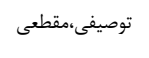 & Weber(2016) & ارتباطات بين فرهنگى در انكولوزى: حالشها و علايق آموزشى \\
\hline 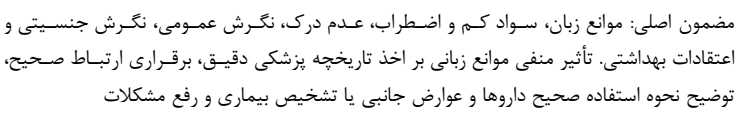 & & كيفى & Taylor(2013) & موانع ارتباطات بين فرهنكَى در مراقبت سلامت \\
\hline 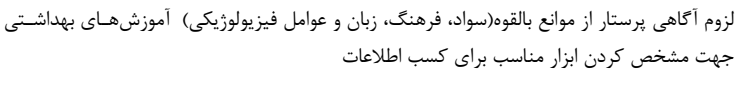 & & 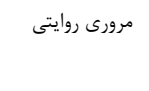 & Beagley(2011) & آموزش بيماران: شناخت موانع، شيوههاى يادكيرى و تكنيكهاى آموزش \\
\hline 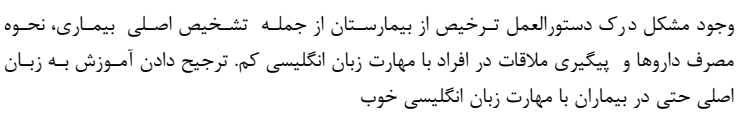 & & 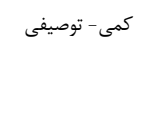 & Karliner(2012) & موانع زبان و درك آموزش ترخيص از بيمارستان \\
\hline و...) ميكى از موانع آموزش از ديدگاه يرستاران ناتوانى در برقرارى ارتباط با قوميتهاى ايرانى(ترى زبان، لر & & 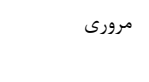 & Faeze(2016) & بررسى حالشهاى يِيش رو در آموز شهاى يرستارى متناسب با نياز بيماران \\
\hline 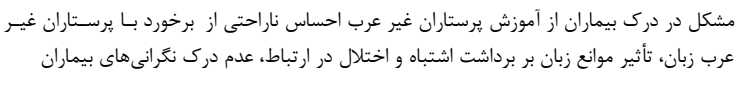 & & بر برسى مقطى & Al-Khathami(2010) & تأثير مانع زبان بيمار و يرستار بر رضايت بيماران \\
\hline متارى و بيماران. ارتباط بين دانشجويان يرستارى و بيماران: تفاوت ز بان محاورهاى بين دانشجويان يـر & & 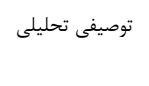 & Haghighi(2019) & 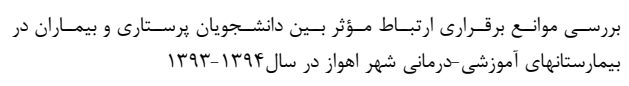 \\
\hline 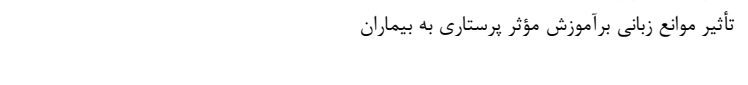 & & توصيفى مقطعى & Jebali(2015) & 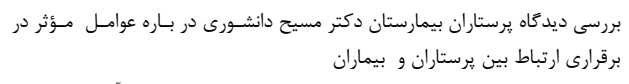 \\
\hline يكى از موانع برقرارى ارتباط از ديدكاه بيماران: آشنا نبودن يرستار به زبان & & توصيفى تحليلى & $\begin{array}{r}\text { Baraz } \\
\text { Pordanjani(2010) }\end{array}$ & برازى موانع برقرارى ارتباط مؤثر يرستار - بيمار در بيمارستان هـاى آموزشى شـهر \\
\hline آشنا نبودن يرستار به زبان محلى بيمار از موانع مهم در برقرارى ارتباط موثر با بيمار & & توصيفى -مقطعى & Habibzadeh(2019) & مورانع برقرارى ارتباط مؤثر يرستار - بيمار از ديدكاه دانشجويان يرسـتارى دانشـكده \\
\hline آشنا نبودن يرستار به زبان محلى بيمار از موانع مهم در برقرارى ارتباط موثر با بيمار & & 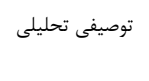 & Saeedi(2018) & 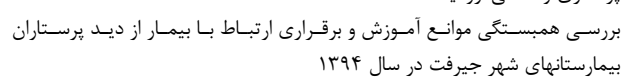 \\
\hline 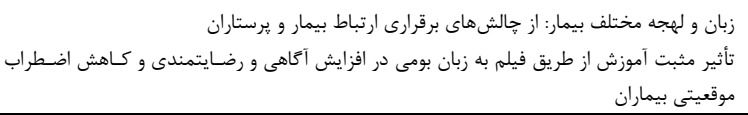 & نيمه & 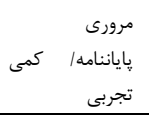 & $\begin{array}{r}\text { mazhariAzad(2019) } \\
\text { Shahmari(2014) }\end{array}$ & 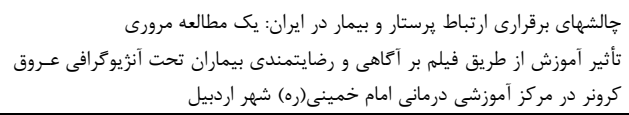 \\
\hline
\end{tabular}


تاكنون كمبود اطلاعات در مورد اين موضوع در دنيا و بخصـوص در

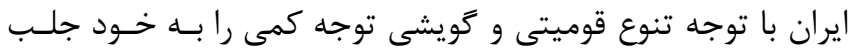
كرده است، كه ممكن است بيانكر اين باشد كه افرادى كه بـهـ زبــان

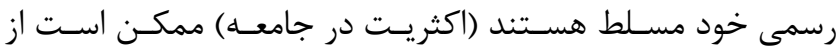
مشكل آكاه نباشند. با اين حال، انتظار مىرود اين مسئله با توجه به مهيه

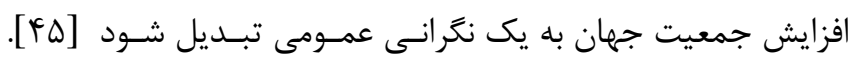

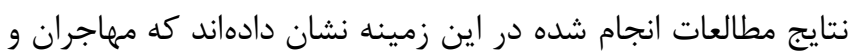
يناهند

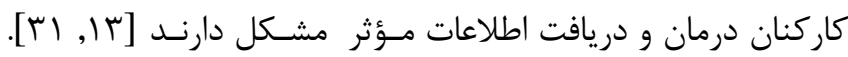
همجنين با توجه به تعدد قوميت و گويشهاى متنوع در ايسران هـهم

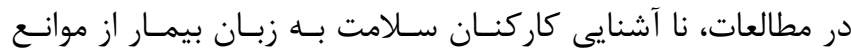

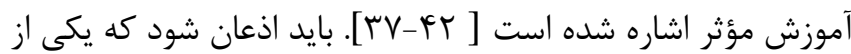

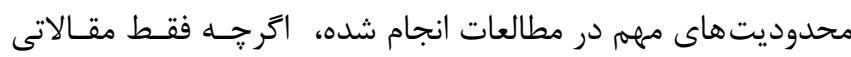
كه تأثير موانع زبانى را بر آموزش و ارتباط با بيمار را بررسـى كـرده مهابه

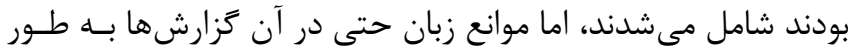
كامل بررسى نشده بود. هدف از آموزش به بيمار ايجاد رفتارهاى مثبت در بيمار است. بيمار و تيه درمانى بر اساس نيازهاى سلامت فردى، اجتمـاعى و ظرفيـت

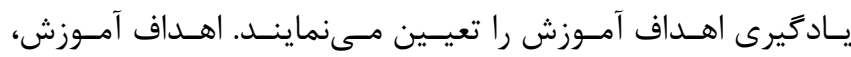

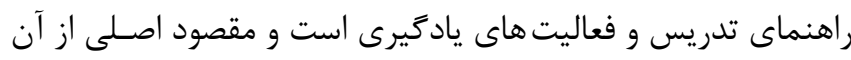
ارزشيابى است تا معلوم نمايد كـهـ آيـا رفتارهـاى مناسـب در بيمـار

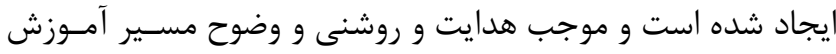

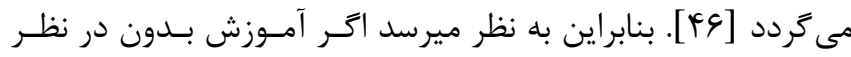

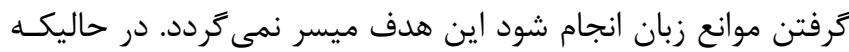

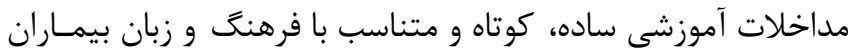

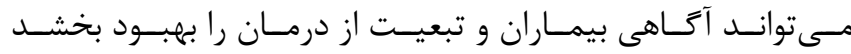

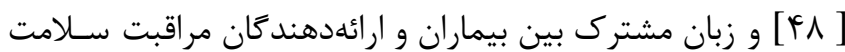
امكان جمع آورى اطلاعات را براى رسـيدن بـه تشـخيص، توضـيح ستراتزى هاى درمانى و اطمينان از درى و تصميمى گيـرى مشـترى

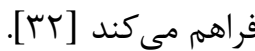

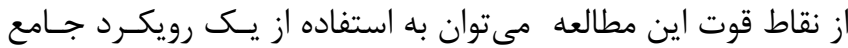
براى جستجوى دادهها از يايگاه دادههاى علمى مربوط، جهت آشكار

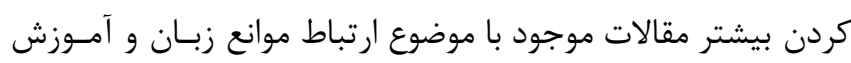

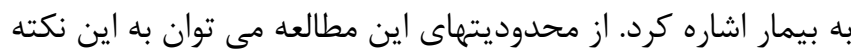

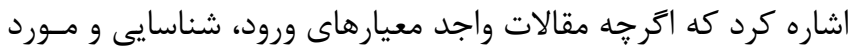
بررسى قرار كرفتند، اما ممكن است بعضى از مطالعات كاغـذى و ويـا

\section{بحث و نتيجه گيرى}

هدف اصلى اين مطالعه، مرورى بر تــأثير موانـع زبـان برآمـوزش بــه بيمار و ارائه راهكارهايى براى مقابله بر اين موانـع بـر اسـاس نتـايج

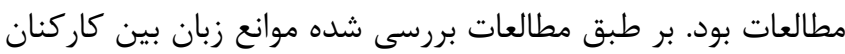

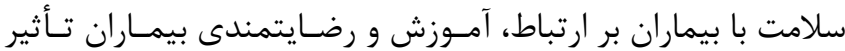
دارد و در صورتى كه زبان اصلى بيماران متفــاوت بـا زبـان كاركنـان

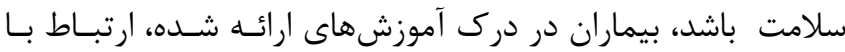
كاركنان سلامت مشكلات بيشترى را تجربه مى كنند. مطالعات در كشورهاى مختلفى انجام شده است، كه به طور كلى در در مربه

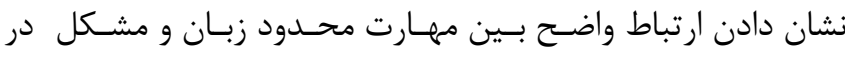

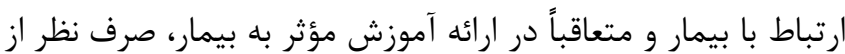

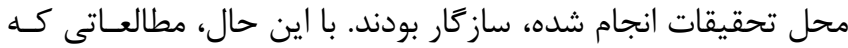

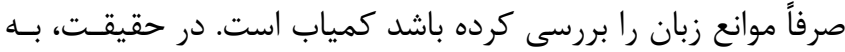

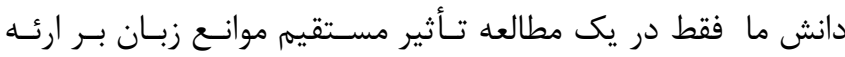

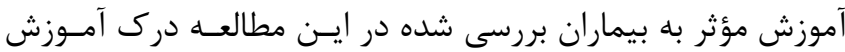

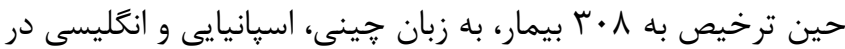

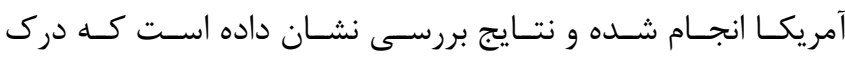

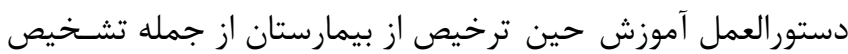
اصلى بيمارى، نحوه مصرف داروهــا و يـيخيـرى ملاقـات در افــراد بــا

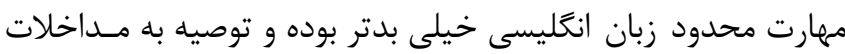

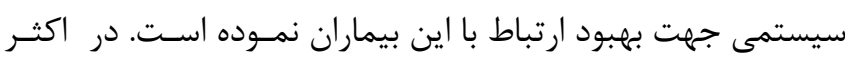

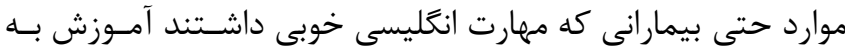
زبان اصلى را ترجيح مىدادند [11]]. مطالعـات بخصـوص مطالعـات

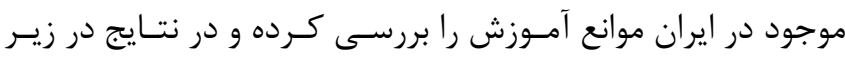

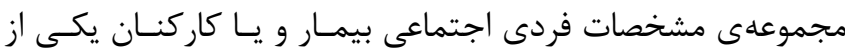
موانع مؤثر در آموزش بيمار، ناآشنايى به زبان بومى و محلـى اشـاره

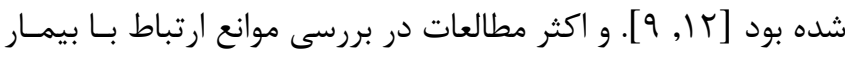

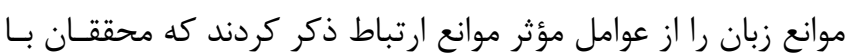
توجه با اينكه لزوم ارائه آموزش مؤثر برقرارى ارتباط مؤثر و به زبـان

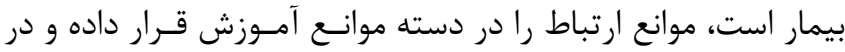

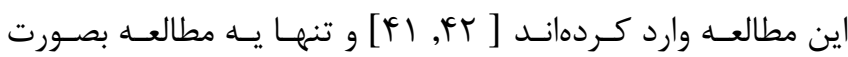
مداخلهاى تأثير آموزش به زبان بومى را بررسى كرده بود و گَزـارش

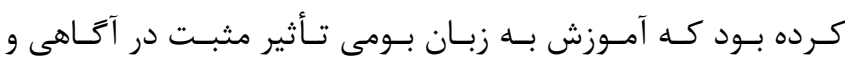

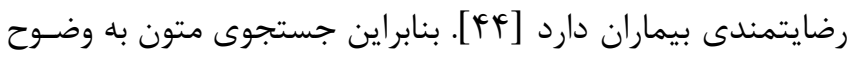

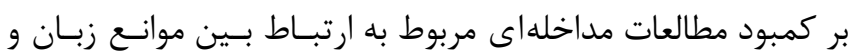

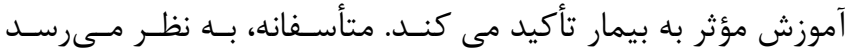


موانع زبان و ارتباط با بيمار و متعاقباً ارائه آمـوزش مـؤثر بــهـ بيمـار

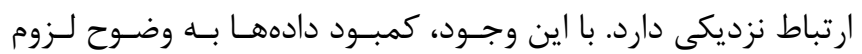

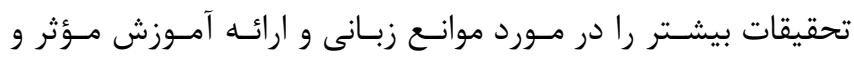

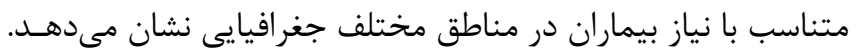

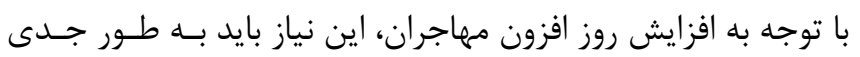
مورد بر بـى قرار كيرد.

\section{سمم نويسند}

مهربان شهمارى: بررسى متون و نكارش پيش نويس مقاله

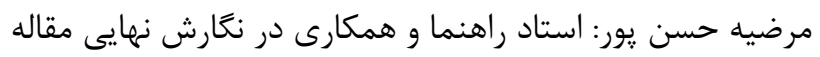

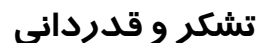

بدينوسيله از تمام محققانى كه مقالات آنهـا در ايـن مطالعـهـ مـورد

$$
\text { بررسى قرار گرفت، تشكر و قدردانى مى تردد. }
$$

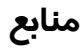

1. Noohi E, Pouraboli B. Educational requirements of the discharged patients and their satisfaction about nursing educational performance, Kerman, Iran. Hormozgan Medical Journal 2009;13: 206-12 [Persian] https://www.sid.ir/en/journal/ViewPaper.aspx?id=164386 2. Krug SE. The art of communication: strategies to improve efficiency, quality of care and patient safety in the emergency department. Pediatric Radiology 2008;38:655-9 DOI: 10.1007/s00247-008-0893-y

3. Agha molaei T, Hasani L. Communication barriers among nurses and elderly patients. Hormozgan Medical Journal 2011; 14:312-318 [Persian] Available from:https://www.sid.ir/en/journal/ViewPaper.aspx?id=194870

4. Bastable SB. Nurse as educator: Principles of teaching and learning for nursing practice. $2^{\text {th }}$ Edition, Jones \& Bartlett Learning: New York, 2017

5. Ignatavicius DD, Workman ML, Mishler MA. Medical-surgical nursing across the health care continuum. $3^{\text {th }}$ Edition, Philadelphia:W.B. Saunders; 1999 URI: http://vlib.kmu.ac.ir/kmu/handle/kmu/87989

6. Falvo D. Effective patient education: A guide to increased adherence. $4^{\text {th }}$ Edition, Jones \& Bartlett Publishers: USA, 2010 books.google.com

7. Habel M. Helping patient family takes charge of their health. Patient Education Journal 2002;31:246-48 8. Marcum J RM, Shaff G, Hammons M, Taylor M. A study of professional nurses' perceptions of patient education[Internet]. Journal of Continuing Education

$$
\begin{aligned}
& \text { منتشرنشده، از دست رفته باشد. علاوه بر اين، مطالعه حاضر تنها بــهـ }
\end{aligned}
$$

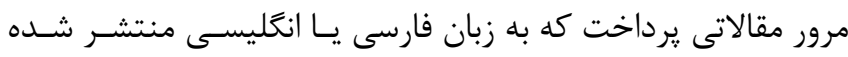

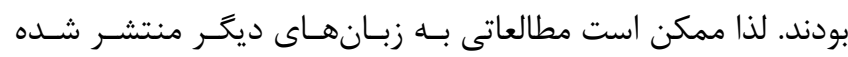

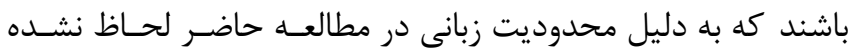

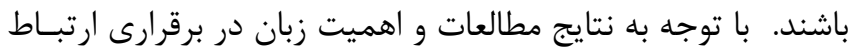

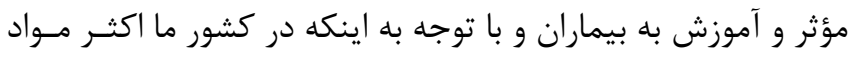

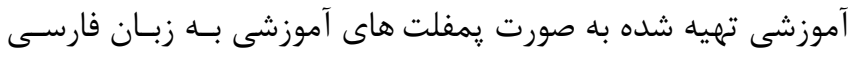

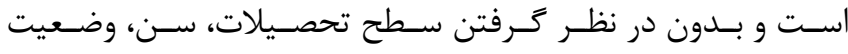

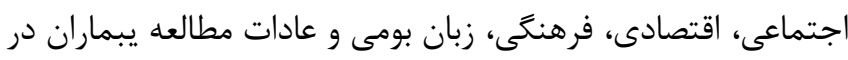

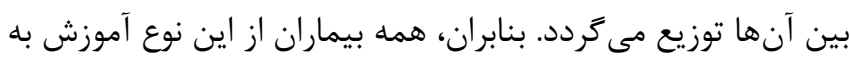

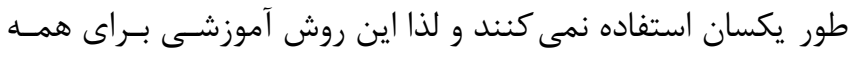

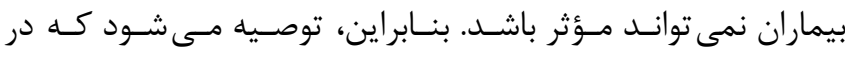

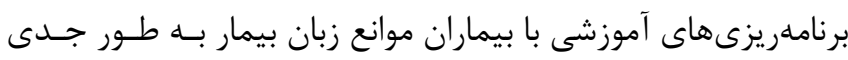

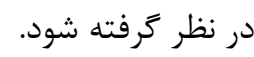

in Nursing 2002; 33:112. https://doi.org/10.3928/0022-012420020501-05

9. Beagley L. Educating patients: Understanding barriers, learning styles, and teaching techniques. Journal of Perianesthesia Nursing 2011;26:331-7 https://doi.org/10.1016/j.jopan.2011.06.002

10. Farahani MA, Sahragard R, Carroll JK, Mohammadi E. Communication barriers to patient education in cardiac inpatient care: A qualitative study of multiple perspectives. International Journal of Nursing Practice 2011;17:322-8

https://doi.org/10.1111/j.1440-172X.2011.01940.x

11. Weber O ,Sulstarova B, Singy P. Cross-Cultural Communication in Oncology: Challenges and Training Interests. Oncology Nursing Forum 2016;43: 24-33 doi: 10.1188/16.ONF.E24-E33

12. Baniyaghoubi F, Talaie Shekari S, Nazari F. Study of the facing challenges in nursing education, related to the patient's needs. Journal of educational studies (NAMA) 2017;5:20-30. [Persian] URL: http://nama.ajaums.ac.ir/article-1-239-fa.html

13. Karliner LS, Auerbach A, Nápoles A, Schillinger D, Nickleach D, Pérez-Stable EJ. Language barriers and understanding of hospital discharge instructions. Medical care Journal 2012;50:283

Doi: 10.1097/MLR.0b013e318249c949

14. Shubayra A. Continuous ambulatory peritoneal dialysis: Nurses' experiences of teaching patients. Saudi Journal of Kidney Diseases and Transplantation 2015;26:309 https://www.sjkdt.org/text.asp?2015/26/2/309/152491 
15. Andriyanto A. Communication barrier between nurse and patient at the hospital :a systematic review. Journal of Health Policy and Management 2019;4:105-10 https://doi.org/10.26911/thejhpm.2019.04.02.05

16. Ferguson WJ, Candib LM. Culture, language, and the doctor-patient relationship. Family Medicine and Community Health Publications and Presentations 2002;61:3 https://escholarship.umassmed.edu/fmch_articles/61

17. Cowan DT, Norman I. Cultural competence in nursing :new meanings. Journal of Transcultural Nursing 2006;17:82-8 https://doi.org/10.1177/1043659605281976 18. Anderson J, Perry J, Blue C, Browne A, Henderson A, Khan KB, et al. "Rewriting" cultural safety within the postcolonial and postnational feminist project: Toward new epistemologies of healing. Advances in Nursing Science 2003;26:196214. DOI: $10.1097 / 00012272-200307000-00005$

19. Anoosheh $\mathrm{M}$, Zarkhah $\mathrm{S}$, Faghihzadeh $\mathrm{S}$, Vaismoradi M. Nurse-patient communication barriers in Iranian nursing. International nursing review 2009;56:243-9. https://doi.org/10.1111/j.1466-7657.2008.00697.x

20. Crawford T, Candlin S. A literature review of the language needs of nursing students who have English as a second/other language and the effectiveness of English language support programmes. Nurse education in practice. $2013 ; 13: 181-5$

https://doi.org/10.1016/j.nepr 2012.09.008

21. Squires A. Strategies for overcoming language barriers in healthcare. Nursing Management 2018;49:20-7. doi: 10.1097/01.NUMA.0000531166.24481.15

22. Ryan CL. Language use in the United States: 2011. American Community Survey Reports 2013 http://statphoneresponse.com/wp-ontent/uploads/2019/01/acs-22.pdf

23. Alshammari M, Duff J, Guilhermino M. Barriers to nurse-patient communication in Saudi Arabia: an integrative review. Biomed central covering nursing 2019;18:61. https://doi.org/10.1186/s12912-019-0385-4

24. Pabon S, Wisotzkey S. ¿ Hablas Inglés? Language barriers in healthcare. Nursing Management 2013;44:19-21. doi: 10.1097/01.NUMA.0000432229.14948.54

25. Keatinge D, Bellchambers H, Bujack E, Cholowski K, Conway J, Neal P. Communication: Principal barrier to nurse-consumer partnerships. International Journal of Nursing Practice 2002;8:1622. https://doi.org/10.1046/j.1440-172x.2002.00344.x

26. Amalraj S, Starkweather C, Nguyen C, Naeim A. Health literacy, communication, and treatment decision-making in older cancer patients. Oncology (Williston Park) 2009;23:369-75

27. Katz MG, Kripalani S, Weiss BD. Use of pictorial aids in medication instructions: A review of the literature. American Journal of Health-System Pharmacy 2006;63:2391-7 https://doi.org/10.2146/ajhp060162

28. Safeer RS, Keenan J. Health literacy: the gap between physicians and patients. American family physician 2005 Aug 1;72:463-8. PMID: 16100861

29. Salazar SI. Language barriers in healthcare information: Communicating with bilingual users. User Experience 2010;9:36-54

30. Poureslami I, Nimmon L, Doyle-Waters M, Rootman I, Schulzer M, Kuramoto L, et al. Effectiveness of educational interventions on asthma self-management in Punjabi and Chinese asthma patients: a randomized controlled trial. Journal of Asthma 2012;49:542-51 doi:

10.3109/02770903.2012.682125. PMID: 22715910

31. Taylor SP, Nicolle C, Maguire M. Cross-cultural communication barriers in health care. Nursing Standard 2013; 27:35-43

doi: $10.7748 / \mathrm{ns} 2013.04 .27 .31 .35$.e7040. PMID: 23641636

32. Partida Y. Language and health care. Diabetes Spectrum2012;25:19-22 https://doi.org/10.2337/diaspect.25.1.19

33. Arksey H, O'Malley L .Scoping studies: towards a methodological framework. International Journal of Social Research Methodology 2005;8:19-32. https://doi.org/10.1080/1364557032000119616

34. World Health Organization. Essential public health functions: a three-country study in the Western Pacific Region. Manila: WHO Regional Office for the Western Pacific; 2003 apps.who.int

35. Moher D, Schulz KF, Simera I, Altman DG. Guidance for developers of health research reporting guidelines. PLoS Medical 2010;7:e1000217. doi: 10.1371/journal.pmed.1000217. PMID: 20169112; PMCID: PMC2821895 36. Tricco AC, Lillie E, Zarin W, O'Brien KK, Colquhoun H, Levac D, et al. PRISMA extension for scoping reviews (PRISMA-ScR): checklist and explanation. Annals of Internal Medicine 2018;2:467473. doi: 10.7326/M18-0850. Epub 2018 Sep 4. PMID: 30178033

37. Haghighi S, Rooeintan M. Effective Communication Barriers between Nursing Students and Patients from Nursing students' Point of View in Ahvaz in 2013-14. Educational Developement of Jundishapur 2019;9:148-57 [Persian]

38. Jebali B, Ghazanjani E.Assessing nurse's viewpoint affiliated to Dr. Masih Daneshvari Hospital in Tehran about effective factors in communication between nurses and patients. Education \& Ethics in Nursing 2015;3:47-53. [Persian]

URL: http://ethic.jums.ac.ir/article-1-242-fa.html

39. Baraz Pordanjani SH, Shariati A, Alijani $\mathrm{H}$. Assessing barriers of Nurse-patient's effective communication in educational hospitals of Ahwaz. 
Iranian Journal of Nursing Research 2010;5:45 Available from:

https://www.sid.ir/en/journal/ViewPaper.aspx?id=179165. [Persian]

40. habibzadeh $\mathrm{h}$, dehgannejad $\mathrm{j}$, hoseinzadeghan $\mathrm{f}$, bafandehzendeh $\mathrm{m}$. Barriers to establishing effective communication between nurse and patient according to nursing students' viewpoints urmia nursing and midwifery faculty. Nursing and Midwifery Journal 2019;17:696-704 http://unmf.umsu.ac.ir/article-1-3743-fa.html. [Persian]

41. Mazhariazad F, Taghadosi M, Erami E. Challenges of Nurse-Patient Communication in Iran: A Review Study. Scientific Journal of Nursing, Midwifery and Paramedical Faculty 2019 10;4:15-29

URL: http://sjnmp.muk.ac.ir/article-1-181-fa.html. [Persian]

42. Saeedi Geraghani H, Nouhi E. Investigation of barriers to educating and establishing communication with patients from nurses' perspective in hospitals of jiroft city in 2015. Journal Nursing Education 2017;6:

1-7 URL: http://jne.ir/article-1-572-en.html [Persian]

43. Al-Khathami AM, Kojan SW, Aljumah MA, Alqahtani H, Alrwaili $\mathrm{H}$. The effect of nurse-patient language barrier on patients' satisfaction. Saudi Medical Journal 2010;31:1355-8. PMID: 21136000

44. Shahmari.M. Effect of video education on knowledge and satisfaction of patients undergoing coronary angiography, Imam Khomeini (RA) Hospital in Ardabil. [MSN dissertation]. Tabriz, Iran: Tabriz University of Medical Sciences Faculty of Nursing and Midwifery; 2013; 68-94

45. Blue L, Espenshade TJ. Population momentum across the demographic transition. Population and Development Review 2011;37:721-47

https://doi.org/10.1111/j.1728-4457.2011.00454.x

46. Mohajer T. Patient education: patient education guide to all members of the healthcare team. $3^{\text {th }}$ Edition, Salemi: Tehran, 2001 [Persian]

47. Shahmari M, Dashti S, Ameli S, Khalilzadeh S, Hosseinian A. Effect of video education in native language on vital signs caused by anxiety in coronary angiography patients. Journal of Ardabil University of Medical Sciences 2016;16:241-50. Available: https://www.sid.ir/en/journal/ViewPaper.aspx?id=526927

48. Abdollahzadeh F, Moghaddasian S, Rahmani A, Shahmari M. Effect of video education on knowledge and satisfaction of patients undergoing coronary angiography. Iran Journal Critical care Nursing 2014;7:168-75. Available from:

https://www.sid.ir/en/journal/ViewPaper.aspx?id=401842 